\title{
Research on the Practice of Sex Education in British Family and School
}

\author{
Shuoyang $\mathrm{Hu}^{1, \mathrm{a}, *},{ }^{*}$, Yijing Zhan ${ }^{2, \mathrm{~b}, *}, \uparrow$ \\ ${ }^{1}$ Education and Languages Department, Major in English, St. Paul University Quezon City, Quezon City, 1112, Metro \\ Manila, Philippines \\ ${ }^{2}$ School of Sociology, Politics and International Studies, University of Bristol, Beacon House, Queens Road, Bristol, \\ BS8 $1 Q U, U K$. \\ ${ }^{*}$ Corresponding author.Email: ${ }^{a} S Y H U @ s p u q c . e d u . p h,{ }^{b}$ cn19094@bristol.ac.uk \\ Those authors contributed equally.
}

\begin{abstract}
Britain ranks a high abortion rate among countries in Western Europe, and the rate of adolescent sexual activity is gradually increasing over the past four decades. Unhealthy sexual behavior can be related to the increase in teenage pregnancy and sexually transmitted diseases, which usually result in negative social and physical consequences for both mothers and children. Effective health promotion and comprehensive sex education to deliver sexual knowledge and bring up a positive sexual attitude is desired for young people in the UK. As family and school play vital roles in the formation of young people's consciousness and the acquisition of knowledge, the purpose of this article is to critically analyze the shortcomings of sex education provided by families and schools in the current British society through the retrospective study of existing research. Suggestions are also provided regarding the responsibilities of family members in sex education issues, reasonable school curriculum and other social support for further improvement of sex education for young people.
\end{abstract}

Keywords: Sex Education, Young People, Family, School.

\section{INTRODUCTION}

\subsection{Sex Education in the United Kingdom (UK)}

\subsubsection{The necessity of sex education for young people in the UK}

Around half of the 16-year-olds worldwide are sexually active, and partner turnover [1]. In Western Europe, The United Kingdom ranked top among countries in teenage birth rate [2], with an annual birth rate of 30 legal terminations per 1000 for women aged 15-19 [3]. Britain also has the highest abortion rate in Western Europe, 22 per 1000 for people under 20 in 1997 [4]. While not necessarily unintentional, teenage pregnancy is frequently linked to negative social and physical consequences for both mother and child, resulting in both individual and societal expenditures. Over the last four decades, the rate of adolescent sexual activity has risen gradually and regularly [5]. The considerable teenage sexually active rate may accelerate the transmission of sexually transmitted diseases (STIs), which is highest among young people. According to a study, approximately $60 \%$ of all new HIV diagnoses are among young individuals, with sexual transmission accounting for more than $90 \%$ of these infections [1]. However, the rate of childbearing has fluctuated, which appears to be linked to intervention-related variables such as access to and use of contraceptive services, as well as the overall atmosphere around young people's sexual health [4]. In the research held by Dawson, they retrospectively reviewed the impact of formal sex education - specifically, instruction regarding pregnancy and birth control — on adolescent premarital intercourse, understanding and use of contraceptive methods, and experience with premarital pregnancy. Their study reveals that sexually active adolescents who have received formal sex education report knowing how to utilize more techniques than those who have not and that the former are more inclined to practice contraceptive knowledge at certain times. Those who had received pregnancy and contraceptive instruction were also more likely to use a certain technique during their first intercourse [6]. This experimental result was supported 
by the research of Visser and Bilsen, in which a literature review was conducted to investigate the impact of sex education and birth control education on contraceptive knowledge and attitudes among young people in Western countries. The study implies that sex education enhanced understanding of sexuality and birth control, and there was also a shift in mentality with teenagers adopting a more liberal and accepting attitude toward sexuality in many situations [7]. The majority of studies related to sex education demonstrate that the education provided had a favorable influence on contraceptive usage, particularly those that directly integrated the intended behaviors into the guidance course. Overall, it can be concluded that there is a need for more effective health promotion and more comprehensive sex education for young people in the UK.

\subsubsection{Designing sex education for young people in the $U K$}

Health education can be defined as any combination of learning experiences to enable voluntary acts favorable to health $[1,8]$. As sexuality is an essential element of healthy development for young people, the World Health Organization and the 1994 International Conference on Population and Development have highlighted the relevance of healthy sexual development to overall mental and physical well-being [9]. The appropriate type of sex education that should be provided in the UK continues to be a major topic of discussion. According to Green and Kreuter, health promotion combines educational and environmental supports for healthpromoting behaviors and living environments [8]. From a more ecological notion of health promotion, individuals' sexual health is considered a function of their surroundings, including their families, social networks, organizations, and public policy frameworks [10]. Therefore, "health behavior" refers to individual activity and the behaviors of groups and organizations [1]. Consequently, the UK's education of healthy sex behavior should not merely be guidance provided for sexually active individuals, but a more comprehensive intervention planned to cover each of these levels related to sexual health. According to WHO, sexual health has recently been defined as a state of physical, emotional, mental, and social well-being related to sexuality, that includes (1) the absence of disease, dysfunction, or infirmity; (2) a positive and respectful attitude towards sex and sexual relations; (3) the ability to have a safe and pleasant sex experience without coercion, discrimination and violence; (4) respect for the rights of all human beings [11].

\subsubsection{The current situation and needs of sex education at home and school}

It is incomplete that sex education can only be finished by family or school. According to Buston et al., the relationship between the social class's supplies and demand and the school's openness with parents is complex [12]. This implies that the implementation of successful sex education requires the support of families and schools and the cooperation of parents and educators, and the joint efforts of other social factors. Appropriate sex education is an important necessity, especially for minors. Walker believes that knowledge, social skills, attitudes, and values are essential dimensions for sex education [13]. As the place where most students' communication and social behavior occur, schools should assume the responsibility of teaching sexual knowledge. However, Buston et al. in 2010 mentioned that Sex education is gradually being marginalized because as people pay more attention to examination subjects, academic subjects occupy the main position of the school curriculum, while non-examination subjects such as sex education are gradually being placed in the marginal position. The implementation of sex education has added difficulties [12].

Besides, Holland et al. also mentioned that young people feel shy to talk to their parents about sex. They do not want to be considered sexually active by their parents, so they are worried about taking the initiative to ask such questions [14]. However, according to Balding in 1999, young people are the ones who need to talk about these sex-related topics with their parents because they are seeking guidance in this special field [15].

\subsubsection{The necessity of developing sex education at home}

Parents play a key role in the formation of children's cognition. In order to lay a solid foundation for the school's follow-up sex education, parental guidance on sex education is very important. With the physical development and changes of adolescents, their demand for sex education is gradually increasing. Young people need to be given the correct boot to satisfy their eagerness for "unknown things about sex" physically and mentally. According to the opinion presented by Wellings et al., as young people reach puberty, they are not only adjusting the change that happened to biological, psychological, and social roles. They are also seeking knowledge, lacked information, and support [16].

\subsubsection{The necessity of developing sex education at school}

Nevertheless, sex education is not only the responsibility of parents. Schools play an important role in youth education. Although the Department for Education's Circular 5/94 (DFE) states that parents are the key to assisting their children's personal and sexual development, teachers should supplement and assist the role of parents, which is regarded as the primary responsibility of educators [13]. Another key issue that 
parents and schools should pay attention to is that young people's behaviors in terms of sexual health are not optimistic. The second national (UK) study of sexual attitudes and lifestyles has proved that men and women who had not addressed sexual topics with their parents and relied heavily on friends and others were less likely to take contraception [16]. In order to provide proper knowledge about sex, hoping to reduce the teenage pregnancy rate and the rate of sexually transmitted diseases, this research will focus on studying the current status of sex education in British families and, analyzing the existing problems of sex education and proposing solutions to optimize those problems.

\section{PREVALENCE OF SEX EDUCATION}

Over a quarter of teenagers in the UK are reported to become sexually active before the age of 16, and most adolescents have begun sexual engagement by the age of 18 [4, 17]. However, once young people begin their sexual activity without a proper guide and enough knowledge, they will have to face the high possibility of facing serious consequences. According to Upchurch and Kusunoki, teens do not use contraception consistently, although teen sex can have severe consequences, such as unintended pregnancies, HIV, and other sexually transmitted illnesses [18]. Therefore, sex education is particularly important for the underage. Some teachers and parents are unprepared and still, need to be confident when putting sex education into practice [19]. Many adults think doing an open discussion about sex is not easy, same with the teachers [12]. Besides, informal sex education of some parents is marked by a type of emotional labor that goes unnoticed. These parents appear to spend a lot of time and energy debating what to say, feeling anxious [13]. Due to the serious consequences caused by teens without a proper guide and enough knowledge and the difficulties which parents and teachers are facing, providing complete and correct guidance and sex education is obligatory for the young since they also need proper guidance more related experiences. According to the Health Education Authority's (HEA) research, parents are expected to pass on information about "facts of life" to their children by young people [20].

\subsection{Practicing Sex education in Britain}

\subsubsection{The necessity and current situation of parents' engagement in sex education at home}

The role of parents taking part in sex education should not be blanked. They are essential people who must take the responsibility to provide sex education to the young. As legislation has promoted that, parents play an important part in children's sex education [13]. They have the right to keep their children out of sex education that is not part of the National Curriculum [13]. Besides, engaging parents in discussions about sexual health and sex alongside their children influence future generations' sexual health [13]. In family education, mothers take the greater responsibility, according to several related studies. Many UK studies claim that sex education at home is provided by the mother [21]. Not all fathers are indeed absent from family sex education. However, according to Walker in 2001, Fathers appear to have very little interaction when they delegate responsibilities to a female in the family or school [22]. Mothers are still considered as the main provider of sex education. Walker also mentioned that the biological sex of the parents, as well as their personal sex education experiences, definitely impact the sex education they offer [22]. Thus, fathers are encouraged to join the family sex education, to share the responsibility with the mother, especially to teach the boys who are always ignored compared to girls about sex education since they have the same gender. Parents appear to believe that there can be no clear sign with boys that might offer the motivation for starting sexual talks, such as menstruation [23]. Further methods focusing on sex education between father and son will be discussed in the following part.

\subsubsection{Difficulties of sex education delivered in schools}

In the United Kingdom and many other Western countries, the negative repercussions of adolescent sexual behavior call up concern for many. As schoolbased sex education being reported as one of the crucial sources of sexual information [24], the current policy on sex education of the UK Government highlights the provision of skills for 'safe sex' at school, intending to minimize unsafe sexual behavior, teenage pregnancy rate, and poor sexual relationship quality. A collection of studies has shown that school's provision of sexual intervention led to positive impacts, including an increase in self-reported knowledge for prevention of Sex Transmitted Infections (STIs), the utilization of contraceptive methods [25] and a reduction in risky sexual behavior shortly after the intervention was provided [26]. However, school-based sex instructions in the UK are not a straightforward process but with multiple problems. As school-based sex education was stated to be the primary source of information for students on sexuality, the arrangement of the curriculum should be taken into good consideration. However, according to Buston, current legislation has not provided a context to support provisional standardization. The party which takes the responsibility of sex education even differentiates in England, Wales and Scotland. The shortage of legislation does not merely lead to ambiguous responsibility of in charge departments but also a 'patchy' situation in providing prescriptive guidance for sex education in British schools. Not until 2000 did Scotland announce guidelines for local authorities on what should be delivered regards sex education programs 
[27]. Before that, it was developed varied in schools. The absence of legislation and clear guidance led to a wide room for consistency in both the time of provision and the type of education provided. A quantitative study which drew on data from 25 schools in Scotland reveals that the sex education being delivered by some individual teachers is significantly less than it by other educators in some Scottish schools, even they followed the same guideline of Personal and Social Education (PSE)-based sex education [12]. The study also discovers that the combination of information provision and discussion of values and background becomes a feature of the curriculum in most schools. However, only a few schools offer skills-based elements. This conclusion coincides with another experiment held by Wight et al. that sex education in the third and fourth years ranged from 7 to 12 lessons in 12 controlled schools, and the content mainly devoted to providing information and discussions. Only two schools regularly demonstrate practical advice on dealing with condoms, and there is no systematic development of negotiation skills [28].

As the promotion of sexual health has become an essential part of health promotion, the official guidelines of England clearly state that sex education based on personal and social education (PSE) is desirable [29]. Expectations for the role of schools in considering and shaping the social and moral aspects of student life is increasing, the responsibility of delivering sex-related knowledge falls off the school agenda. Meantime, with the annual release of ranking tables and the standardization of examination subjects, subjects with higher academic status become more and more privileged, while other subjects become more marginalized. Consequently, schools and teachers are facing tremendous pressure to balance the curriculum and bear the burden of rising teenage pregnancy rates in the UK [12].

Besides, the topics related to sexuality have long been 'taboo' for many. Given that the anxiety and fear associated with sex and sexuality still exist, it is not surprising that when attention is focused on the content and methods of delivering sex education, controversy arises [12]. Three educational patterns were compared by Kohler et al. to examine their effectiveness, respectively. His research showed that compared with no sex education, respondents who had comprehensive sex education are significantly related to fewer pregnancies and slightly related to the lower likelihood of sexually active; surprisingly, respondents with has nothing to do with these two results. Neither intervention significantly reduced the incidence of sexually transmitted infections [30]. The ineffectiveness of abstinence-only education was also supported by Stanger-Hall et al. that increasing emphasis on abstinence education positively correlates with teenage pregnancy rates and fertility rates. In this case, a comprehensive method of sex education that integrates STD education is of great necessity [31].
Except for the set of curriculums and the pattern of provision, the effectiveness of school-based sex education has a relation to the correctness of school in addition. A teacher-led randomized controlled trial of sex education in Scotland found no difference between the intervention group and the control group in terms of subsequent conception and termination of treatment [32]. Recognizing that the connection with school may affect the sexual risk-taking behavior of adolescents, especially in terms of leading to teenage pregnancy $[26,33]$.

\section{IMPROVEMENT OF SEX EDUCATION}

\subsection{Methods of improving domestic sex education}

When it comes to encouraging domestic sex education, satisfying the teen's need is one aspect of improving sex education. In the previous part, the Health Education Authority's (HEA) research already showed the needs of teenagers to learn knowledge about sex [20]. Besides, communication is important in solving the sexual-related problem and delivering knowledge about sex education. Parents need to make sure the environment of sex education at home is appropriate and acceptable enough for both parents and children to lessen the awkward and embarrassing feeling when talking about such a sensitive topic. According to Walker, three significant studies have found that creating a talking atmosphere at home is one of the most important variables impacting sex education in the home [13].

Meanwhile, since sex education cannot be completed only by schools, parents should cooperate with the school and fulfill the responsibilities and obligations of sex education as their children's first teacher. Furthermore, the Department for Education's (DFE) Circular 5/94 advice states unequivocally that parents are the most important factor in their children's personal and sexual development in 1994 [34]. Furthermore, teachers are supposed to complement and assist the role of parents, as they are viewed as having the primary duty [34]. In addition, parents should set correct role models in front of their children, no matter for settling a model of following the right measurements of protecting themselves in sexual related questions or situations or teaching their children in advance about how to perform good sex education at home. Parents, according to Sharpe et al., can be essential role models [23]. Regardless of their gender or sexual orientation, adolescents require accurate information, sexually significant role models, emotional support, relational support, and chances to grow as people and sexual decision-makers [35]. Furthermore, parents should emphasize boys' sex education, and fathers should be particularly involved. Boys are not like girls who have a clear sign such as menstruation, for parents to start sex education [23]. Furthermore, fathers must be encouraged to be more 
informed and honest and recognize their unique position in discussing sexual matters with the boys through health promotion activities [13].

Last but not least, if the child who needs to receive sex education has siblings, parents can also involve them in this whole procedure for creating a comfortable and acceptable environment for the child to learn. Although "peer" means the people around the same age as the particular child, no matter their siblings or classmates inside the school, the word "peer education" here refers to the child's siblings who need to receive domestic education. Peer engagement appears to boost confidence in discussing sexual issues, allowing for beneficial improvements in sexual knowledge and attitudes about future sexual behavior and relationship confidence. Peer educators are seen as having more informal interactions, such as chatting openly, laughing, and utilizing humor while passing on important health information [36]. Another essential element impacting peer relationships is the biological sex of the peer educator and power dynamics. Furthermore, sibling participation may confirm and promote sex education messages delivered by parents or other family members [13]. As a result, in domestic sex education, siblings will be learners and otherwise teachers, delivering sex education to their younger brothers and sisters. In Hatami's research, the involvement of trained peers in a formal educational course could well be utilized to informally provide relevant educational knowledge to their uneducated peers, attempting to optimize teens' sexual health [37]. Additionally, parents who are urged to incorporate other siblings into sex education may feel less stressed and alone in delivering sex education inside the family due to these strategies [13]. If possible, parents can also ask for help from their community if their community has services about sex education provided by some peer education organizations. A clear definition is shown in the study of Roy et al. Peer education, in most cases, is based on democratic visions of acquiring knowledge and transmitting skills. It frequently operates outside established education systems and institutions enshrined in stratified certification that restricts access to only appropriately skilled elites at successive levels [38]. Parents can, however, enlist aid from their older children at home to cope with their younger child's sex education or seek sex education from local community or peer education groups.

\subsection{Implications for the practice of sex education in schools}

It can be drawn from the research that most successful interventions use a multi-component approach to address a range of personal and structural risk determinants [26], requiring not only the schools' efforts but also the result of the joint efforts of various aspects. Due to the nature of sex education being problematic, individual teachers responsible for designing sex education programs differ in their motivations, perspectives, values, and experiences [12]. These are essential for determining the nature of formal sex education programs. In addition, except for the traditional teacher-and-adult-led sexual health education in schools, there is a tendency for school-peer-led education. Reports have shown that social factors such as family and peers have been linked to adolescent sexual performance [39]. There is evidence that peer-led methods are more likely to lead to conservative sexual attitudes, while adult-led educators are better at imparting factual knowledge. Evidence suggests that learning about sex from a friend of the same age or the first boy/girlfriend can also reduce the risk of STIs, similar to the results achieved in the school sex education course [26]. Therefore, it is vital to provide support training for school staff who take the responsibility of delivering sexual health education, which should be designed to minimize the influence of individual educators and enhance the social skills related to maintaining sexual relations.

The effectiveness of sex education in school attaches importance to the curriculum settings of schools as well. School's attitude towards sex education and the planning of educational time and content significantly affects students' mastery and understanding of sexual knowledge. According to a previous study, there is a lack of advice on practicing sexual health knowledge [28]. Practical instruction such as the correct usage of condoms should be put into the program designing as it may affect the intention of condom application [26].

The realization of successful sex education requires the school's efforts and multiple efforts from various components in society. The improvement of the quality of sex education requires the development of school education skills and the allocation of educational resources, and the wider social and cultural issues related to matters surrounding sexuality, including assistance for instructors in disputes with parents and the mass [12].

\section{CONCLUSION}

This article analyzes the shortcomings of sex education in the UK from the two main perspectives of family and school and provides suggestions for improvement. Talking about sex education, whether at home or school, is always embarrassing and sometimes regarded as "taboo". In order to strengthen sex education, it is recommended that parents talk to young people in a relaxed environment with their siblings, and boys should be specially targeted. Schools should adopt multiple methods to achieve the integration of family and school education. A unified and reasonable domestic sex education curriculum is of great necessity, which cannot be separated from the support of policies. In addition, the entire community should discuss sex issues more inclusively and provide appropriate teacher training on 
sex education. Further research should develop openness to talk about sex, develop pragmatic sex education, and promote parent-school cooperation. It is hoped that with the joint efforts of all parties, the quality and effectiveness of sex education can be further improved to reduce the rate of teenage pregnancy, risky sexual behaviors, and the probability of sexually transmitted diseases.

\section{REFERENCES}

[1] Schaalma, H. P., Abraham, C., Gillmore, M. R., \& Kok, G. (2004). Sex education as health promotion: what does it take?. Archives of sexual behavior, 33(3), 259-269.

[2] Kane, R., \& Wellings, K. (1999). Reducing the rate of teenage conception, an international review of the evidence: data from Europe. Health Education Authority.

[3] Office for National Statistics, London (United Kingdom);. (1996). Birth statistics Review of the Registrar General on births and patterns of family building in England and Wales, 1994; laid before Parliament pursuant to Section 19 Registration Service Act 1953.

[4] Statistics, A. (1974). Legal abortions carried out under the 1967 Abortion Act in England and Wales. London: HSMO.

[5] Wellings, K., \& Kane, R. (1999). Trends in teenage pregnancy in England and Wales: how can we explain them?. Journal of the Royal Society of Medicine, 92(6), 277-282.

[6] Dawson, D. A. (1986). The effects of sex education on adolescent behavior. Family Planning Perspectives, 162-170.

[7] Visser, A. P., \& van Bilsen, P. (1994). Effectiveness of sex education provided to adolescents. Patient education and counseling, 23(3), 147-160.

[8] Green, L. W., \& Kreuter, M. W. (1993). Health promotion planning: An educational and ecological approach. McGraw-Hill.

[9] Shtarkshall, R. A., Santelli, J. S., \& Hirsch, J. S. (2007). Sex education and sexual socialization: Roles for educators and parents. Perspectives on sexual and reproductive health, 39(2), 116-119.

[10] Richard, L., Potvin, L., Kishchuk, N., Prlic, H., \& Green, L. W. (1996). Assessment of the integration of the ecological approach in health promotion programs. American journal of health promotion, 10(4), 318-328.
[11] World Health Organization (2002). Retrieved from https://www.who.int/reproductivehealth/topics/gen der_rights/sexual_health/en/

[12] Buston, K., Wight, D., \& Scott, S. (2001). Difficulty and diversity: the context and practice of sex education. British Journal of Sociology of Education, 22(3), 353-368.

[13] Walker*, J. (2004). Parents and sex educationlooking beyond 'the birds and the bees'. Sex education, 4(3), 239-254.

[14] Holland, J., Mauthner, M., \& Sharpe, S. (1996). Family matters: Communicating health messages in the family. London: Health Education Authority.

[15] Balding, J., \& Exeter Univ.(United Kingdom). Schools Health Education Unit;. (1999). Young People in 1998: And Looking Back as Far as 1983: the Health Related Behaviour Questionnaire Results for 18,221 Young People Aged 12-13 and 14-15 in 1998, and Approximately 200,000 Since 1983. University of Exeter, Schools Health Education Unit.

[16] Wellings, K., Nanchahal, K., Macdowall, W., McManus, S., Erens, B., Mercer, C. H., ... \& Field, J. (2001). Sexual behaviour in Britain: early heterosexual experience. The lancet, 358(9296), $1843-1850$.

[17] Willetts, M. C., Sprecher, S., \& Beck, F. D. (2004). Overview of Sexual Practices and Attitudes Within Relational Contexts.

[18] Upchurch, D. M., \& Kusunoki, Y. (2006). Adolescent sexual relationships and reproductive health outcomes: Theoretical and methodological challenges. Romance and sex in adolescence and emerging adulthood: Risks and opportunities, 221 231.

[19] Buston, K., Wight, D., Hart, G., \& Scott, S. (2002). Implementation of a teacher-delivered sex education programme: obstacles and facilitating factors. Health education research, 17(1), 59-72.

[20] HEA (1999) Reducing the rate of teenage conceptions. Young people's experiences of relationships, sex and early parenthood: qualitative research (London, HEA)

[21] Allen, I. (1987). Education in sex and personal relationships (No. 665). Policy Studies Institute.

[22] Walker, J. L. (2001). A qualitative study of parents' experiences of providing sex education for their children: The implications for health education. Health Education Journal, 60(2), 132-146. 
[23] Sharpe, S., Mauthner, M., \& France-Dawson, M. (1996). Family health: a literature review. Health Education Authority.

[24] Zhang, L., Li, X., \& Shah, I. H. (2007). Where do Chinese adolescents obtain knowledge of sex? Implications for sex education in China. Health Education.

[25] Yu, J. (2010). Sex education beyond school: Implications for practice and research. Sex Education, 10(2), 187-199.

[26] Vivancos, R., Abubakar, I., Phillips-Howard, P., \& Hunter, P. R. (2013). School-based sex education is associated with reduced risky sexual behaviour and sexually transmitted infections in young adults. Public Health, 127(1), 53-57.

[27] McCABE, M. I. K. E. (2000). Report of the working group on sex education in Scottish schools. Edinburgh: Scottish Executive.

[28] Wight, D., Raab, G. M., Henderson, M., Abraham, C., Buston, K., Hart, G., \& Scott, S. (2002). Limits of teacher delivered sex education: interim behavioural outcomes from randomised trial. Bmj, 324(7351), 1430.

[29] Forrest, J., Souter, N., \& Walker, S. (1994). Personal Relationships and Developing Sexuality. A Staff Development Resource for Teachers. Vol. 1-3. University of Strathclyde, Faculty of Education.

[30] Kohler, P. K., Manhart, L. E., \& Lafferty, W. E. (2008). Abstinence-only and comprehensive sex education and the initiation of sexual activity and teen pregnancy. Journal of adolescent Health, 42(4), 344-351.

[31] Stanger-Hall, K. F., \& Hall, D. W. (2011). Abstinence-only education and teen pregnancy rates: Why we need comprehensive sex education in the US. PloS one, 6(10), e24658.

[32] Henderson, M., Wight, D., Raab, G. M., Abraham, C., Parkes, A., Scott, S., \& Hart, G. (2007). Impact of a theoretically based sex education programme (SHARE) delivered by teachers on NHS registered conceptions and terminations: final results of cluster randomised trial. bmj, 334(7585), 133.

[33] Bonell, C., Allen, E., Strange, V., Copas, A., Oakley, A., Stephenson, J., \& Johnson, A. (2005). The effect of dislike of school on risk of teenage pregnancy: testing of hypotheses using longitudinal data from a randomised trial of sex education. Journal of Epidemiology \& Community Health, 59(3), 223-230.
[34] Department for education (1994) Sex education in schools, Circular No 5/94, Education Act 1993: Sex education in schools (London, HMSO).

[35] Giami, A., Ohlrichs, Y., Quilliam, S., Wellings, K., Pacey, S., \& Wylie, K. R. (2006). Sex education in schools is insufficient to support adolescents in the 21st century: A summary of sexual and relationship therapy's inaugural debate, held at the 8th Congress of the European Federation of sexology in Prague, 5 June 2006. Sexual and Relationship Therapy, 21(4), 485-490.

[36] Strange, V., Forrest, S., \& Oakley, A. (2002). Peerled sex education - characteristics of peer educators and their perceptions of the impact on them of participation in a peer education programme. Health Education Research, 17(3), 327-337.

[37] Hatami, M., Kazemi, A., \& Mehrabi, T. (2015). Effect of peer education in school on sexual health knowledge and attitude in girl adolescents. Journal of education and health promotion, 4, 78. https://doi.org/10.4103/2277-9531.171791

[38] Fisher, R., \& Fisher, P. (2018). Peer education and empowerment: perspectives from young women working as peer educators with Home-Start. Studies in the Education of Adults, 50(1), 74-91.

[39] Edgardh, K. (2002). Sexual behaviour and early coitarche in a national sample of 17-year-old Swedish boys. Acta Paediatrica, 91(9), 985-991. 